\title{
Leveraging Online Annotation Tool to Enhance Cohesion in Writing of Malay Language Students in Singapore Primary Schools
}

\author{
Suryani Atan \\ Educational Technology Division, Singapore Ministry of Education
}

\begin{abstract}
The project aimed to systematically build students' ability to write cohesively with a set of learning design that leveraged the affordances of online annotation tool. It was conducted in 10 schools by 12 teachers to 300 Primary 4 Malay Language students age 10 years old in 2016. It was designed to address the lack of writing skills in students to connect their ideas in a cohesive manner as lamented by teachers. The tool enabled highlighting and making comments to online compositions, thus supporting collaborative learning and peer evaluation which enabled improvement on pupils' own compositions. The specially designed lesson package focused on cohesive devices such as 'additive', 'adversative', 'causal' and 'temporal' [5], [9], [10]. Impact on students was captured through various means such as lesson observations, survey and discourse analysis of students' compositions, showing positive behaviour and the ability to write cohesively and extensively.
\end{abstract}

\section{Introduction}

Writing as the highest language skills, requires many practices. This includes learning to develop storyline, generate ideas, and connecting those ideas to form a cohesive writing. With the avail of technologies, teachers are able to leverage them for teaching and learning. Kumar and Tammelin [21] reported positive benefits of technologies in language teaching and learning such as motivation and skills, concentration, cognitive processing, independent learning, critical thinking and teamwork. Therefore, this project has leveraged the affordances of information and communication technologies in teaching and learning. It was conducted with the objective to systematically build students' ability to write cohesively with a set of learning design that leveraged the affordances of online annotation tool.

\section{Background}

The project leveraged the annotation tool in the 10 'M portal (see Figure 1). The portal was developed and managed by Educational Technology Division (ETD) of Singapore Ministry of Education (MOE) to support experimentations in the teaching and learning of the Malay Language with the use of information and communication technologies (ICT).
Introduced in 2008, this portal was used in conjunction with a teaching and learning programme that fronts innovative ICT use for engaged learning to promote pupils' interest and hone their skills in Mother Tongue Languages such as Chinese (C) Language, Malay (M) Language, and Tamil (T) Language.

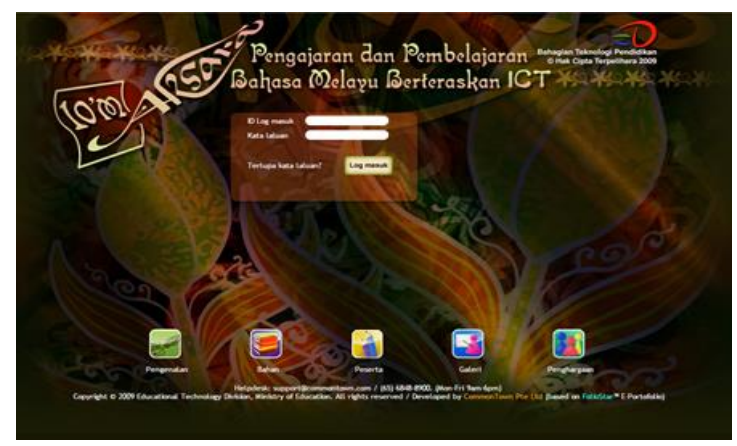

Figure 1. 10’M Portal

It was collectively referred to as $10^{\prime} \mathrm{CMT}$. The $10^{\prime} \mathrm{CMT}$ programme made the most of the opportunities offered by ICT in achieving studentcentred learning environment. It enhanced the teaching-learning process by providing interactive learning experience that could be customised to cater to different learning abilities. In addition, this programme fostered self-paced independent learning and provided opportunities for collaborative learning.

The 10'CMT pedagogical approach incorporated a 2-1-1 structure that represents $50 \%$ of teacher teaching time, $25 \%$ of students' practice time, and $25 \%$ of students' output time. The time set aside for students promoted self-paced independent learning during curriculum time. This helped to further student's own effort to acquire knowledge. This was further enhanced by the one to one computing environment. Each student worked individually and collaboratively online. Teachers in the programme could also leverage on the affordances of an array of ICT tools that enabled individual and collaborative work to be conducted comfortably online. Teachers could set differentiated tasks for students to customise to their learning needs. Through thoughtful design of the 10'CMT lesson, students we given: (1) ample time for online reading and self-construction of knowledge; (2) ample opportunities for self- 
improvement before evaluation; and (3) appropriate avenue for online collaboration through peer editing, online rubrics for self-peer-teacher evaluation and peer-to-peer comments and feedback. This programme had the ability to increase students' interest and motivation to learn the Mother Tongue Languages.

The affordances such as annotation tool in the portal was leveraged in conjunction with a specially designed lesson package that focused on connecting ideas in composition writing. The study was conducted in 10 schools by 12 teachers to 300 Primary 4 students age 10 years old. This project was designed to address the lack of writing skills in students to connect their ideas in a cohesive manner as lamented by teachers. These anecdotal evidences were further affirmed by a discourse analysis of their students' compositions before intervention. Quantitative findings from the discourse analysis showed very little or non-existence of any discourse devices that connects ideas between sentences or between paragraphs.

\section{Concept of Cohesion}

The language focus of the project was the concept of cohesion. According to Halliday and Hasan [5], “... cohesive in writings refers to its semantics in which we see meanings that exist within a text. Therefore, we see cohesion between sentences from the way sentences are structured. In fact, we can see cohesion within the sentence or cohesion between two sentences or more".

Halliday and Hassan [5] further concluded that "The concept of cohesion is a semantic one; it refers to relations of meaning that exist within the text...cohesion in sentences could be explained as a structural relation... (however) this (project) will be of cohesion across sentence boundaries."

Therefore, how do we show cohesion within or in between sentences? We use conjunctions. By definition, conjunctions are words that express certain meanings which presuppose the presence of other components in the discourse. Therefore, if a cohesive element is used within a sentence, it is structural. If it happens between sentences, it is cohesive.

According to Halliday and Hasan, "Conjunctive elements are cohesive not in themselves but indirectly, by virtue of their specific meanings: they are not primarily devices for reaching out into the preceding (or following) text, but they express certain meanings which presuppose the presence of other components in the discourse."

They elaborated further with an example of the conjunction 'and' that can be both structural and cohesive [5]. For example, the following example shows a structural relation:

- (3.1) John and Mary went to school.
On the other hand, the following examples show cohesive relation [5]:

- 'I wonder if all the things move along with us?' thought poor puzzled Alice. And the Queen seemed to guess her thoughts, for she cried 'Faster! Don't try to talk!'

- 'At the end of three yards I shall repeat them - for fear of your forgetting them. At the end of four, I shall say goodbye. And at the end of five, I shall go!'

- He heaved the rock aside with all his strength. And there in the recesses of a deep hollow lay a glittering heap of treasure.

- 'While you're refreshing yourself,' said the Queen, 'I'll just take the measurements.' And she took a ribbon out of her pocket, marked in inches ...

Halliday and Hasan [5] refer to the conjunctive 'and' in examples (3.2) - (3.5) by the more general term 'additive' to suggest something rather looser and less structural than is meant by coordinate 'and' in example (3.1).

For this project, it was decided to explicitly teach conjunctive elements such as additive, adversative, causal and temporal cohesive elements [4].

\subsection{Additive}

Additive relations often seem to have the sense of 'there is something more to be said'. The ideas said after these additive conjunctives are additional information to the idea before this. Some examples of additive elements are and, or, furthermore, moreover, additionally, besides that, in addition, for example, and similarly. For example:

- I couldn't send all the horses, you know, because two of them are wanted in the game. And I haven't sent the two Messengers either.

- My client says he does not know this witness. Further, he denies ever having seen her or spoken to her.

\subsection{Adversative}

The basic meaning of the adversative relation is 'contrary to expectation'. The expectation may be derived from the content of what is being said, or from the communication process, and the speaker-hearer situation. Examples of adversative elements are yet, 
but, however, nevertheless, despite this, on the other hand, actually, instead, and on the contrary. For example:

- All the figures were correct; they'd been checked. Yet the total came out wrong.

- He showed no pleasure at hearing the news. Instead he looked even gloomier.

\subsection{Causal}

Causal conjunctives give some kind of reasoning or argument from a premise. Examples of causal elements are so, thus, therefore, consequently, because of this, with this intention, because, under the circumstances, with regard to this, and as a result. For example:

- The very first thing she did was to look whether there was a fire in the fireplace, and she was quite pleased to find that there was a real one and blazing away as brightly as the one she had left behind. 'So, I shall be as warm here as I was in the old room,' thought Alice.

- You aren't leaving, are you? Because I've got something to say to you.

\subsection{Temporal}

Temporal conjunctives show relation between the theses of two successive sentences in terms of sequence in time and that one is subsequent to the other. Examples of temporal elements are then, next, afterwards, after that, subsequently, thereupon, on another occasion, next moment, in a moment, in the end and finally. For example:

- 'Tickets, please!' said the Guard, putting his head in at the window. In a moment everybody was holding out a ticket.

- 'There's no sort of use in knocking,' said the Footman, 'and that for two reasons. First, because I'm on the same side of the door as you are; secondly, because they're making such a noise inside, no one could possibly hear you.'

\subsection{Application}

These sub-types - additive, adversative, causal and temporal - were applied in a beautiful example given by Halliday and Hasan [5] as follows:

"For the whole day he climbed up the steep mountainside, almost without stopping. And, in all this time he met no one. Yet, he was hardly aware of being tired. So, by night time, the valley was far below him. Then, as dusk fell, he sat down to rest."

The various cohesive elements - 'and' (additive), 'yet' (adversative), 'so' (causal) and 'then' (temporal) - weaved the ideas in the prose beautifully. These were the missing elements that were mentioned earlier. In addition to teaching student's beautiful phrases such as figure of speech and interesting vocabulary, there should be a need to teach them cohesive elements in their compositions so that their ideas could be linked in a more cohesive manner.

\section{Specially Designed Lesson Package}

Included in the specially designed lesson package (see Figure 2), the pedagogical structure that was created based on scaffolding approach and Bloom's Taxonomy - identify, select, construct, and write. Also, resources such as lesson plan, videos, picture composition, learning tasks, were uploaded to the portal. The lessons also followed a timeline on the teaching sequence and were thematically aligned with the national curriculum instructional materials. The following diagram shows the three components available in the lesson package created:

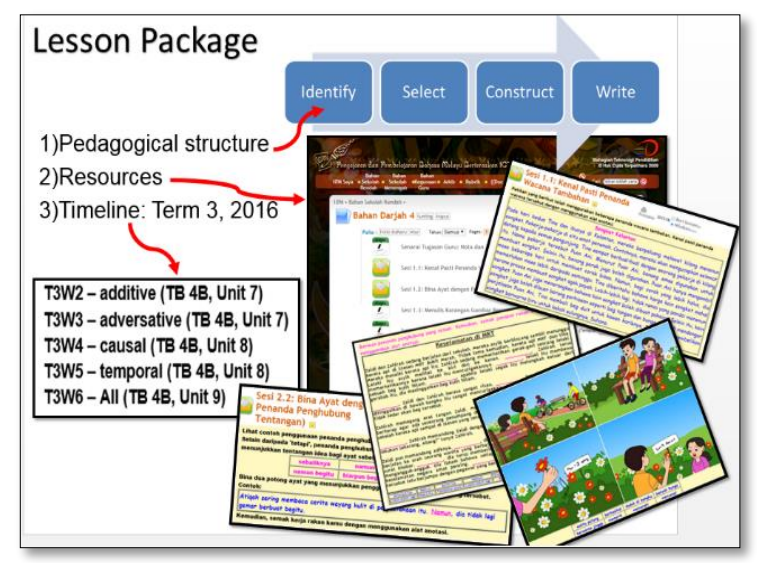

Figure 2. Lesson Package 
The lesson flow is outlined in Figure 3.

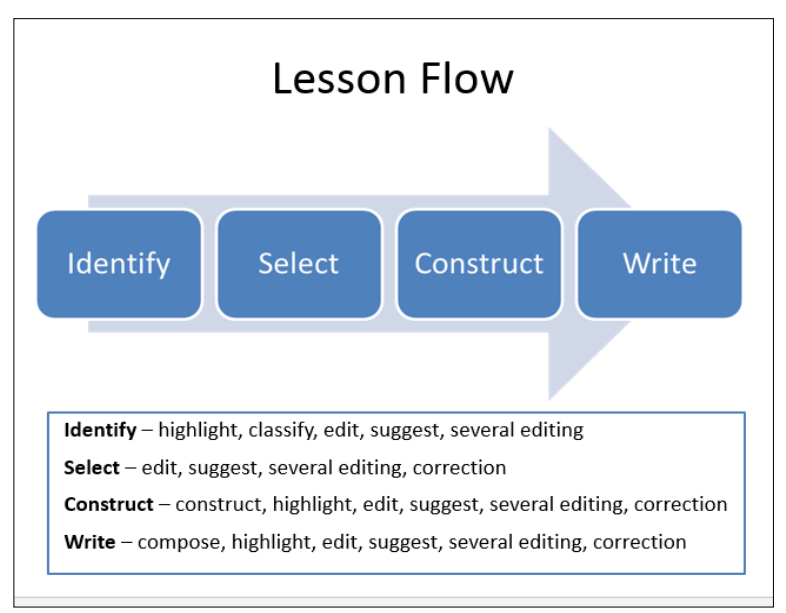

Figure 3. Lesson Flow

Firstly, students identified the cohesive devices in a given passage. Secondly, students selected suitable cohesive devices to fill in the blanks of a given passage. Thirdly, students constructed two sentences and linked the ideas by using cohesive devices. Lastly, students wrote compositions and conscientiously use the cohesive devices that they have learnt. And, after every step, students would have to evaluate, edit, or provide suggestions to their peers' work.

\section{Online Annotation Tool}

But why ICT? Can we do without ICT? Yes, we can. However, we can do better with ICT. Literature review has shown positive impact on learning language with technologies. Kumar and Tammelin researched on 'Integrating ICT into Language Learning and Teaching' in 2008 in Europe [21]. The findings affirmed that the three main benefits of ICT are the followings:

First, ICT provides language learners with the opportunity to use the language that they are learning in meaningful ways in authentic contexts. The use of current and authentic materials is motivating for the language learner.

The second important benefit derived from the use of ICT in a language classroom is the opportunities it affords for cooperation and collaboration with one's peers. Students can write and speak to each other in real-time. Students are able to write, read, speak, listen and react to a conversation using ICT as part of the language learning process. The overall role of the teacher has changed from the traditional authoritative role to that of a facilitator.

The third major benefit is the opportunity that ICT-based tools give to language teachers so that they can tutor their learners more effectively. Teachers are able to give individual and personalised guidance to students with different learning styles needs.
The annotation tool available in the $10^{\prime} \mathrm{M}$ portal allowed students to highlight and add comment or suggestion without modifying the original text itself. It could be thought of as a layer on top of the existing text and this annotation layer was usually visible to other users who shared the same portal, therefore supporting collaborative learning amongst students. The tool allowed students to identify cohesive devices used in a text, comment and suggest suitable cohesive devices, and also exchange ideas during online collaborative activities.

The following are examples of how this tool (see Figure 4) was leveraged during lesson:
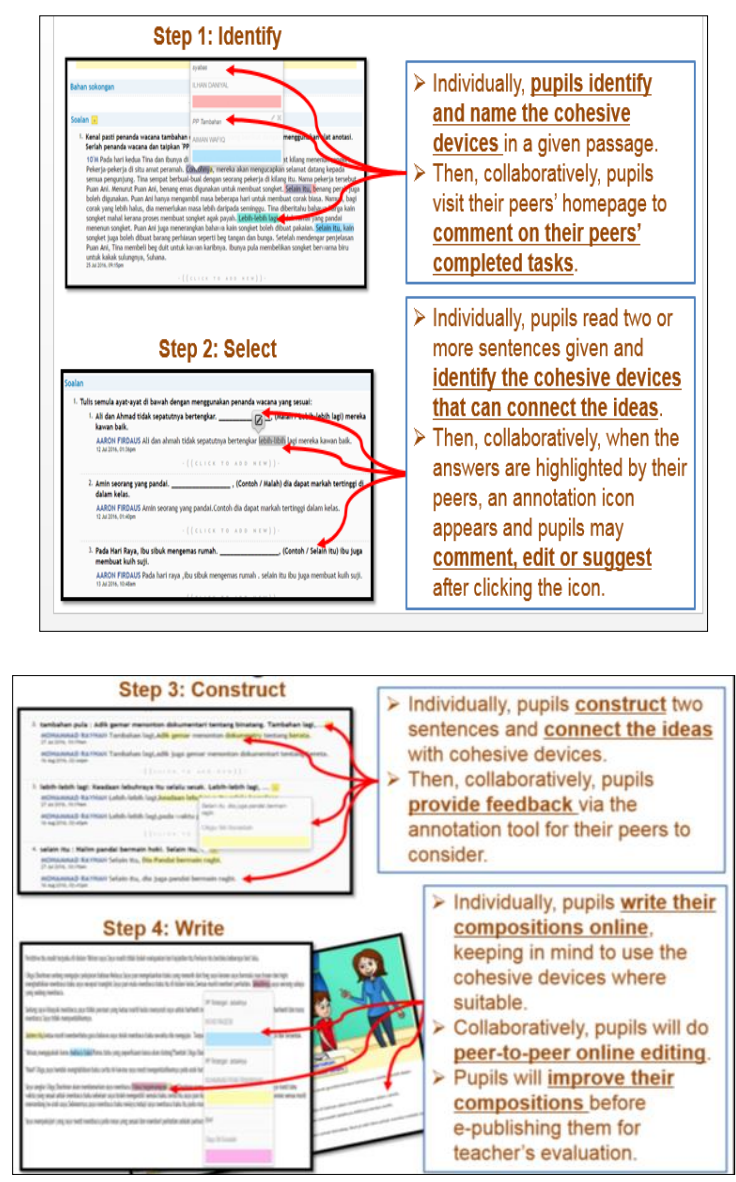

Figure 4. Leveraging Online Annotation Tool

\section{Research Design and Methodology}

This study involved 300 primary four students from 10 schools. Data were collected through classroom observations (qualitative) and discourse analysis of students' compositions for the pre and post-test data (quantitative). Classroom lesson observations were conducted for every group. Because Design-based research is based on contextually dependent interventions, postconferences were conducted after every lesson observations to inform teachers of ways to further improve the lesson. For quantitative data, the pre-test 
(SA1, mid-year examination) and post-test (SA2, endyear examination) compositions were analysed on the use of cohesive device. In addition, feedbacks from teachers and students were collected for triangulation.

The research design adopted was Design-based research. This research design was a systematic but flexible methodology aimed to improve educational practices through iterative analysis, design, development, and implementation, based on collaboration among researchers and practitioners in real-world settings. Design-based research advances design, research and practice concurrently.

According to Wang and Hannafin [19], Designbased research was initially advanced by Brown [22] and Collins [23] as design experiments. It promotes synergistic relationships among researching, designing, and engineering. Design-based research challenges the assumption that research is contaminated by the external influence of the researcher [24]. Instead, researchers manage research processes in collaboration with participants, design and implement interventions systematically to refine and improve initial designs, and ultimately seek to advance both pragmatic and theoretical aims affecting practice.

Design-based research implementations need to be both purposeful and systemic. To achieve these, researchers need to practice nine principles central to planning and implementing such as (1) support design with research from the outset; (2) set practical goals for theory development and develop an initial plan; (3) conduct research in representative real-world settings; (4) collaborate closely with participants; (5) implement research methods systematically and purposefully; (6) analyse data immediately, continuously, and retrospectively; (7) refine designs continually; (8) document contextual influences with design principles; and (9) validate the generalizability of the design.

There are five basic characteristics of Designbased research:

\subsection{Pragmatic}

Design-based research refines both theory and practice. The value of theory is appraised by the extent to which principles inform and improve practice.

\subsection{Grounded}

Design is theory-driven and grounded in relevant research, theory and practice. Design is conducted in real-world settings and the design process is embedded in, and studied through, design-based research.
Designers are involved in the design processes and work together with participants. Processes are iterative cycle of analysis, design, implementation, and redesign. Initial plan is usually insufficiently detailed so that designers can make deliberate changes when necessary.

\subsection{Integrative}

Mixed research methods are used to maximize the credibility of ongoing research. Methods vary during different phases as new needs and issues emerge and the focus of the research evolves. Rigor is purposefully maintained, and discipline applied appropriate to the development phase.

\subsection{Contextual}

The research process, research findings, and changes from the initial plan are documented. Research results are connected with the design process and the setting. The content and depth of generated design principles varies. Guidance for applying generated principles is needed.

\section{Findings and Discussion}

Impact on pupils was captured through various means such as lesson observations and discourse analysis, showing positive behaviour and the ability to write cohesively and extensively. For example, findings from lesson observations showed that students were highly motivated in their learning. They were comfortable in using annotation tool for the purpose of identifying, editing and providing insights for individual work and also for collaboration among peers. In addition, they were observed to be enthusiastic, engaged and diligent. Findings from the discourse analysis of students' compositions showed an increase in the number of correct use of cohesive devices. Their compositions were longer with more details and descriptions. Students were able to produce a more cohesive composition by connecting the ideas using suitable cohesive devices. The following is an example of improvement (see Figure 5) shown by a student:

The discourse analysis of the composition showed that there was no cohesive devices used in the pre-test composition. After the intervention, the student could write not just cohesively, but extensively as well. It was because students have used more details and explanations to show the meaning and functions of the cohesive devices used.

\subsection{Interactive, Iterative, and Flexible}




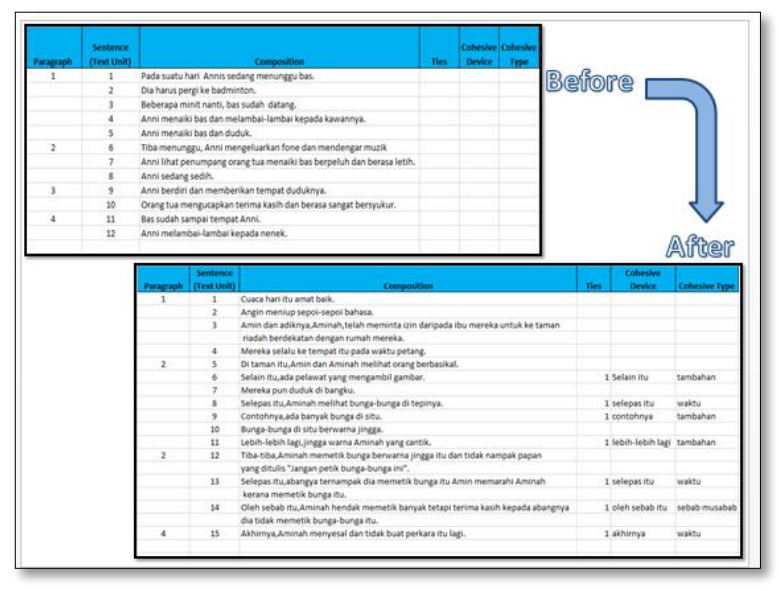

Figure 5. Discourse Analysis - Pre \& Post-Test

Thus, also making their writing cohesive because the ideas were carefully linked.

Overall, analysis of the students' compositions showed that there was an increase in the number of cohesive devices used. In their SA2 compositions, the two most frequent type of cohesive devices used were 'additive' and 'temporal' while two least used were the 'adversative' and 'causal'.

\section{Conclusion}

This project was designed and conducted in 2016 to 300 students in 10 schools after anecdotal evidences and discourse analysis of the students' composition showed the lack of cohesive devices that connect the ideas in their writing. Thus, technology such as online annotation tool was leveraged to improve students' ability to write cohesively. Together with a specially designed lesson package that focused on connecting ideas in composition and guided by a cohesion model that was adapted accordingly, positive impact was achieved after the intervention. The students have shown positive behaviour in their learning during the lesson observations, and the ability to write cohesively and extensively through discourse analysis of their compositions after the intervention.

\section{References}

[1] Cazden, C. B., (2001). Classroom Discourse: The Language of Teaching and Learning. Portsmouth, NH: Heinemann

[2] Comeaux, P., \& McKenna-Byington, E., (2003). "Computer-mediated communication in online and conventional classroom: Some implications for instructional design and professional development programmes". Innovations in Education and Teaching International, 40(4), 348-355.
[3] Curriculum Planning and Development Division (2015). Malay Language Syllabus: Primary. Singapore: CPDD, MOE.

[4] Fang, Y. \& Kim-Eng Lee, C. (2010). "Lesson Study and Instructional Improvement in Singapore". Research Brief, $10(1), 1-4$.

[5] Halliday, M.A.K. and R. Hasan (1976). Cohesion in English. London: Longman.

[6] Halliday, M.A.K. dan Christian Matthiessen (2004) (3rd edition). Introduction to Functional Grammar. London: Edward Arnold.

[7] Koh, H.L., et.al. (2015). Design Thinking for Education: Conceptions and Applications in Teaching and Learning. Singapore: Springer

[8] Lewis, C. C. (2002). A Handbook of Teacher-Led Instructional Change. Philadelphia: Research for Better Schools, Inc.

[9] Nik Safiah, et al., (2011). Tatabahasa Dewan. Kuala Lumpur: Dewan Bahasa dan Pustaka

[10] Sanat Md. Nasir (2002). Tautan dalam Wacana Bahasa Melayu Akhbar. Kuala Lumpur: Dewan Bahasa dan Pustaka.

[11] Scardamalia, M. and Bereiter, C., (1994). "Computer Support for Knowledge-Building Communities". Journal of the Learning Sciences, 3(3), 265-283.

[12] Smaldino, S., Lowther, D. \& Russell, J., (2012). Instructional Technology and Media for Learning. Boston, MA: Pearson.

[13] Smith, B. L., \& MacGregor, J. T. (1992). "What is collaborative learning?” In Goodsell, A., Maher, M., Tinto, V., Smith, B., MacGregor, J. Collaborative Learning: A Sourcebook for Higher Education. USA: Pennsylvania

[14] Stepanek, J., Appel, G., Leong, M., Turner Mangan, M., Mitchell, M., (2007). Leading Lesson Study: A Practical Guide for Teachers and Facilitators. Cambridge. California, USA: Sage.

[15] Atan, S., (2013). "Towards a Collaborative Learning Environment Through ICT: A Case Study". Sino-US English Teaching, 10(1), 53-57.

[16] Atan, S., (2013). "Lesson Study on ICT Integrated Lessons: The 10'M Experience". The 1st International Conference on Languages, Literature and Cultural Studies. Burapha University, Thailand, 22 - 24 August 2013.

[17] Atan, S., (2013). "Pemerkasaan Pelajar dalam Pembelajaran Bahasa Melayu menerusi Penerapan ICT" in Penyelidikan Bahasa Melayu. Tanjong Malim, Perak: Universiti Pendidikan Sultan Idris.

[18] Atan, S., (2014). "Lesson Study on ICT-Integrated Lessons: the Singapore Context". The 8th World Association of Lesson Studies (WALS) International 
Conference 2014. Indonesia University of Education, Indonesia, 25 - 27 November 2014.

[19] Wang, F. and Hannafin, M.J., (2005). "Design-Based Research and Technology-Enhanced Learning Environments". Educational Technology Research and Development, 53(4), 5-23

[20] Zhu, C., (2012). "Student Satisfaction, Performance, and Knowledge Construction in Online Collaborative Learning". Educational Technology \& Society, 15(1), 127136.

[21] Kumar, S., \& Tammelin, M., (2008). Integrating ICT into language teaching: Guide for institutions. Johannes Kepler University Linz.

[22] Brown, A. L., (1992). Design experiments: Theoretical and methodological challenges in creating complex interventions in classroom settings. Journal of the Learning Sciences, 2(2), 141-178.

[23] Collins, A., (1992). Toward a design science of education. In E. Scanlon \& T. O'Shea (Eds.), New directions in educational technology (pp. 15-22). New York: SpringerVerlag.

[24] Barab, S.A. \& Kirshner, D., (2001). Guest Editors' Introduction: Rethinking Methodology in the Learning Sciences. Journal of the Learning Sciences, 10(1), 5-15. Retrieved September 22, 2018 from https://www.learn techlib.org/p/165497/.

\section{Acknowledgements}

The author gratefully acknowledges the grant received from the Senior Specialist Track Research Fund (SSTRF), Singapore Ministry of Education to support this research. The author wishes to thank the 10 schools that permitted her to conduct the research in their territories, and the school leaders, teachers, and students who participated in this study. 